\title{
Metabolic and endocrine effects of treatment with peroral or transdermal oestrogens in conjunction with peroral cyproterone acetate in women with polycystic ovary syndrome
}

\author{
J Vrbíková, S Stanická, K Dvořáková, M Hill, K Vondra, B Bendlová and L Stárka \\ Institute of Endocrinology, Prague, Czech Republic \\ (Correspondence should be addressed to Jana Vrbíková, Institute of Endocrinology, Národní 8, Prague 1, 116 94, Czech Republic; Email: \\ jvrbikova@endo.cz)
}

\begin{abstract}
Objective: To compare the influence of transdermal and peroral oestrogen treatments in conjunction with cyproterone acetate (CPA) on metabolic and hormonal parameters in women with polycystic ovary syndrome (PCOS).

Patients and methods: Twenty-four women with PCOS, aged 25.4 \pm 4.3 (mean \pm S.D.) years, body mass index $24.5 \pm 3.9 \mathrm{~kg} / \mathrm{m}^{2}$ were randomly assigned to receive either transdermal oestradiol plus CPA $(n=12)$ or a peroral oestradiol-CPA combination $(n=12)$. Before and after 3 months of treatment, basal blood samples, euglycaemic hyperinsulinaemic clamp combined with indirect calorimetry and arginine tests were performed. ANOVA and Student's t-test or Wilcoxon's test were used for statistical analyses.

Results: After peroral oestradiol-CPA, insulin sensitivity $(P<0.004)$ and the disposition index as the function of insulin sensitivity and secretion $(P<0.0001)$ decreased significantly. Fasting insulin $(P<0.05)$, cholesterol $(P<0.05)$, high-density lipoprotein cholesterol $(P<0.05)$ and sex-hormone binding globulin $(P<0.0001)$ increased significantly. Dehydroepiandrosterone $(P<0.05)$ and 17 $\mathrm{OH}$ progesterone $(P<0.01)$ decreased significantly. After transdermal oestradiol $+\mathrm{CPA}$, no significant changes were observed in sex-hormone binding globulin and androgen concentrations, insulin sensitivity or disposition index.

Conclusions: In women with PCOS, peroral oestrogens (at doses common in combined oral contraceptives) led to a significant impairment in insulin secretion and action. In contrast, the transdermal application of oestrogens did not significantly influence insulin sensitivity.
\end{abstract}

European Journal of Endocrinology 150 215-223

\section{Introduction}

Polycystic ovary syndrome (PCOS) is a common endocrine disorder affecting about $5-10 \%$ of women of fertile age $(1,2)$. In recent decades, insulin resistance has been found to be an integral part of $\operatorname{PCOS}(3,4)$ : women with PCOS are at increased risk of the development of either impaired glucose tolerance or type II (non-insulin-dependent) diabetes mellitus (NIDDM) $(5-8)$.

Combined oral contraceptives remain the first-line therapy for women with PCOS who do not wish to become pregnant. They ameliorate dermatological manifestations of hyperandrogenism, improve menstrual cycle disturbances and may prevent endometrial and ovarian cancer. To date, however, little attention has been given to the metabolic effects of combined oral contraceptives. There is some evidence that they could worsen glucose tolerance (9) and insulin sensitivity in both healthy women and those with PCOS $(10,11)$.

In contrast, most studies conducted in another age group - postmenopausal women - have detected no harmful effects of the application of transdermal oestrogens on insulin sensitivity $(12-16)$. To the best of the authors' knowledge, this method of application of oestrogens has not previously been studied in PCOS, with the exception of one study (17) in which fasting insulin concentrations were lower after the oral administration of $17 \beta$-oestradiol than after the transdermal application of natural oestrogens.

In a randomized, open study in women with PCOS, we have studied the effects of a transdermal oestrogen administered together with oral cyproterone acetate, and of an oral oestrogen-cyproterone acetate combination formulation, on steroid hormone concentrations, 
lipids, insulin resistance and insulin secretion, using the euglycaemic hyperinsulinaemic clamp and arginine tests as reference methods.

\section{Patients and methods}

The study group consisted of 25 oligo/amenorrhoeic women with PCOS matching the National Institutes of

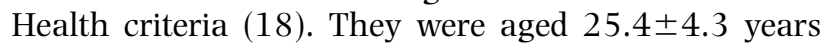
and all had clinical manifestation of hyperandrogenaemia in the form of hirsutism, acne, or both, in addition to an increased free testosterone index or androstenedione concentrations outside the reference range [0.40-2.65 nmol/l for testosterone, $43-95 \mathrm{nmol} / \mathrm{l}$ for sex-hormone binding globulin (SHBG), free testosterone index $>6$ and $1.6-5.4 \mathrm{nmol} / \mathrm{l}$ for androstenedione]. None of the patients had taken oral contraceptives or any other steroid medication during the preceding 3 months and none had taken any other medication influencing insulin sensitivity. The local ethics committee of the Institute of Endocrinology approved the study procedure.

The patients were evaluated at the clinical department as outpatients, and after giving written informed consent they underwent a euglycaemic hyperinsulinaemic clamp in the early follicular phase of the spontaneous menstrual cycle (between days 1-7) combined with indirect calorimetry, and an arginine stimulation test. Both tests were repeated after 3 months of study treatment. Random number tables were used to allocate the women randomly to groups to receive either oral (13 women) or transdermal (12 women) oestrogens. In the peroral group, one woman decided not to undergo the second metabolic examination, and thus eventually 12 women in each group were examined. Women in the peroral group (D) received a combination formulation of oestradiol with CPA (Diane 35; Schering AG, Berlin, Germany) and those in the transdermal group $(\mathrm{E}+\mathrm{CPA})$ received oestradiol (Estraderm TTS 50; (Novartis Pharma AG, Basel, Switzerland) together with CPA (Androcur; Schering AG) $2 \mathrm{mg}$ daily for 21 days in the month.

The waist and hip circumferences were measured to the nearest centimetre with a flexible and nondistensible tape, avoiding exertion of pressure on the tissues and with the individual standing barefoot. The waist circumference was measured midway between the lower limit of the rib cage and the iliac crest. The hip circumference was the maximal circumference over the femoral trochanters.

After basal blood samples had been taken, the indirect calorimetry measurement was performed using Vmax29n (Sensormedics, Yorba Linda, CA, USA) based on the dilution technique and converting gas exchange data to calories using the Weir equation. After $30 \mathrm{~min}$ rest on the bed, the fasting patient was placed under the hood and measurement was carried out until the standard steady state criteria were met.
Subsequently, a $3 \mathrm{~h}$ euglycaemic hyperinsulinaemic (1 mIU/kg per min) clamp was performed as described previously (19). Insulin sensitivity was determined in the interval from 100 to $120 \mathrm{~min}$. Samples for the determination of free fatty acids were taken at 150 , 165 and $180 \mathrm{~min}$.

The following parameters were obtained from the clamp: glucose disposal rate $(\mathrm{M})$ was defined as the amount of glucose supplied by the infusion that was required to maintain the desired blood glucose concentration $(\mathrm{mg} / \mathrm{kg}$ per $\mathrm{min})$. The insulin sensitivity index (ISI) was defined as the ratio of the glucose disposal rate to the average insulin concentration during the period observed $\{[(\mathrm{mg} / \mathrm{kg}$ per $\mathrm{min})$ per $(\mathrm{mU} / \mathrm{l})] \times 100\}$. The metabolic clearance rate of glucose (MCRg, ml/kg per min) was determined as the amount of the infused glucose (in ml) divided by the average blood glucose concentration. The posthepatic clearance rate of plasma insulin (MCRi, l/kg per min) was calculated as the ratio between the rate of infusion of insulin and the steady state plasma insulin concentration.

To evaluate $\alpha$ - and $\beta$-cell secretion, an arginine test was performed as described by Larsson \& Ahren (20). Briefly, intravenous cannulae were placed in antecubital veins on both arms (one for the glucose infusion and the second for sampling). Baseline samples for insulin and glucagon were taken at -5 and $-2 \mathrm{~min}$. Subsequently, $5 \mathrm{~g}$ arginine (diluted in $40 \mathrm{ml}$ physiological solution) was applied as an intravenous bolus at time 0 over a period of $50 \mathrm{~s}$ and samples for insulin and glucagon were taken again at 2, 3, 4 and $5 \mathrm{~min}$. After that, a variable-rate infusion of $15 \%$ glucose solution was commenced, to increase and maintain blood glucose concentrations between 13 and $15 \mathrm{mmol} / \mathrm{l}$. Finally, new baseline samples were taken, the arginine bolus was repeated and new samples for insulin and glucagon were taken at 2, 3, 4 and 5 min thereafter.

Blood glucose was determined in whole blood by an electrochemical method (Super GL, Dr Müller Geráte Bau, GmBH, Freital, Germany). Insulin was estimated and $\mathrm{C}$ peptide was measured using IRMA kits (Immunotech, Marseilles, France). The cross-reactivity of the antiserum with both insulin and glucagon was less than $0.05 \%$. Proinsulin was determined by ELISA (IBL, Hamburg, Germany), with no cross-reactivity with insulin and $\mathrm{C}$ peptide. Glucagon was determined by RIA (IBL).

Total cholesterol and triglycerides were determined enzymatically (reagents from Boehringer Mannheim, using a Cobas Mira S autoanalyser, Hoffman-La Roche, Basel, Switzerland); high-density lipoprotein (HDL)-cholesterol was determined using the same method after precipitation. Free fatty acids (FFA) were determined by the enzymatic colourimetric method, using a kit from WAKO Chemicals (Neuss, Germany).

Testosterone, androstenedione, dehydroepiandrosterone (DHEA), DHEA sulphate (DHEAS), oestradiol, luteinising hormone (LH), follicle-stimulating hormone 
(FSH) and SHBG were determined as stated previously (21). Insulin-like growth factor (IGF)-I was determined using an IRMA kit (Immunotech) with a sensitivity of $3 \mathrm{ng} / \mathrm{ml}$ and intra- and interassay coefficients of variation $(\mathrm{CV})$ of 7.4 and $8 \%$ respectively. IGF binding protein (IGFBP)-3 was determined using an IRMA kit (Immunotech) with a sensitivity of $50 \mathrm{ng} / \mathrm{ml}$ and intra- and interassay CVs of 6.0 and $9.5 \%$ respectively.

\section{Calculations and statistics}

The acute insulin response (AIR) to arginine was calculated as the mean of +2 to +5 min samples minus the pre-stimulus insulin concentration for the fasting values (AIRf) and glucose-potentiated values (AIRg). The slope between AIR at fasting blood glucose and at blood glucose $14 \mathrm{mmol} / \mathrm{l}\left(\right.$ slope $_{\mathrm{AIR}}=\Delta \mathrm{AIR} / \Delta$ glucose $)$ was calculated as a measure of the glucose potentiation of $\beta$-cell secretion. The corresponding acute glucagon responses (AGRf, AGRg) and the slope ${ }_{\mathrm{AGR}}$ were calculated in the same manner. Disposition indices (Di) were calculated according to Kahn et al. (22) using the values of ISI and AIRf (Dif), AIRg (Dig) or slope AIR (Dis).

The anti-lipolytic index was calculated according to Jacob et al. (23), as:

$\left[\mathrm{FFA}_{0}-\left(\mathrm{FFA}_{150}+\mathrm{FFA}_{165}+\mathrm{FFA}_{180}\right) / 3\right] /\left(\mathrm{IRI}_{120}-\mathrm{IRI}_{0}\right)$ where IRI is insulin.

Statistical evaluation was performed using multiway repeated-measures ANOVA with treatment and status as between- and within-factors respectively, and with treatment $\times$ status interaction followed by least significant differences (LSD) multiple comparisons between individual subgroups. Most of the variables were treated by power transformation to achieve a Gaussian distribution of data and homoscedasticity. The variables with absolute values of Studentised residuals greater than 2.5 (outliers) were not included in the model. The treatment effect (treatment with D compared with treatment with E+CPA) was evaluated using the ANOVA model involving the status both before and after medication, and separately in the subgroups of patients treated with $\mathrm{D}$ and with $\mathrm{E}+\mathrm{CPA}$ using LSD multiple comparisons after the ANOVA test. The LSD multiple comparisons were also used for assessment of the differences between the subgroups after medication.

\section{Results}

\section{Clinical parameters}

Body weight, body mass index, waist circumference, waist:hip ratio, and systolic and diastolic blood pressures did not change significantly in either the D- or the E+CPA-treated group (Table 1).

In group $\mathrm{E}+\mathrm{CPA}$, an improvement in menstrual cyclicity was seen in six of the 12 women. In three women, breakthrough bleeding was observed, and in another three, an irregular menstrual cycle was not improved.

Table 1 Clinical, biochemical and hormonal values in women with PCOS before and after treatment with either peroral or transdermal oestrogens together with cyproterone acetate.

\begin{tabular}{|c|c|c|c|c|}
\hline & \multicolumn{2}{|c|}{ Peroral } & \multicolumn{2}{|c|}{ Transdermal } \\
\hline & Before & After & Before & After \\
\hline BMI $\left(\mathrm{kg} / \mathrm{m}^{2}\right)$ & $24.7 \pm 4.0$ & $24.5 \pm 3.5$ & $24.4 \pm 3.7$ & $24.4 \pm 3.8$ \\
\hline WHR & $0.79 \pm 0.06$ & $0.78 \pm 0.07$ & $0.74 \pm 0.05$ & $0.72 \pm 0.06$ \\
\hline $\mathrm{SBP}(\mathrm{mmHg})$ & $113.2 \pm 9.5$ & $116.8 \pm 9.2$ & $116.8 \pm 11.9$ & $115.6 \pm 8.6$ \\
\hline $\mathrm{DBP}(\mathrm{mmHg})$ & $71.3 \pm 5.9$ & $74.3 \pm 5.5$ & $72.4 \pm 8.3$ & $72.3 \pm 7.7$ \\
\hline Total cholesterol (mmol/l) & $4.48 \pm 0.59$ & $5.16 \pm 0.91^{*}$ & $4.13 \pm 0.49$ & $4.00 \pm 0.50$ \\
\hline HDL-cholesterol (mmol/l) & $1.28 \pm 0.27$ & $1.51 \pm 0.24^{*}$ & $1.30 \pm 0.25$ & $1.20 \pm 0.21$ \\
\hline Triglycerides $(\mathrm{mmol} / \mathrm{l})$ & $0.81 \pm 0.30$ & $1.08 \pm 0.35$ & $0.76 \pm 0.20$ & $0.77 \pm 0.23$ \\
\hline Free fatty acids (mmol/l) & $0.66 \pm 0.26$ & $0.57 \pm 0.15$ & $0.84 \pm 0.46$ & $0.95 \pm 0.45$ \\
\hline Blood glucose $(\mathrm{mmol} / \mathrm{l})$ & $4.83 \pm 0.47$ & $4.59 \pm 0.53$ & $4.77 \pm 0.33$ & $4.71 \pm 0.33$ \\
\hline Testosterone (nmol/l) & $2.51 \pm 1.02$ & $2.60 \pm 0.98$ & $2.60 \pm 0.98$ & $2.08 \pm 0.56$ \\
\hline $\mathrm{DHEA}(\mathrm{nmol} / \mathrm{l})$ & $25.9 \pm 12.3$ & $16.0 \pm 8.7^{\star}$ & $30.7 \pm 12.5$ & $23.1 \pm 13.0$ \\
\hline DHEAS $(\mu \mathrm{mol} / \mathrm{l})$ & $5.76 \pm 2.42$ & $4.65 \pm 1.97$ & $7.51 \pm 1.97$ & $7.32 \pm 1.60$ \\
\hline 17-OH progesterone $(\mathrm{nmol} / \mathrm{l})$ & $2.01 \pm 0.77$ & $1.24 \pm 0.67^{* *}$ & $2.03 \pm 0.97$ & $1.70 \pm 0.83$ \\
\hline SHBG (nmol/l) & $41.3 \pm 19.0$ & $173.4 \pm 53.4^{* * * *}$ & $43.7 \pm 20.8$ & $38.9 \pm 17.1$ \\
\hline $\mathrm{LH}(\mathrm{IU} / \mathrm{I})$ & $6.48 \pm 3.62$ & $3.23 \pm 3.90^{* *}$ & $6.20 \pm 3.84$ & $2.94 \pm 2.1^{*}$ \\
\hline FSH (IÚ/I) & $4.1 \pm 1.44$ & $2.72 \pm 2.23$ & $4.69 \pm 1.27$ & $4.36 \pm 1.66$ \\
\hline IGF-I (ng/ml) & $331.4 \pm 114.5$ & $244.6 \pm 101.7^{\star}$ & $311.1 \pm 69.8$ & $314.0 \pm 67.6$ \\
\hline IGFBP-3 (ng/ml) & $3320 \pm 514$ & $33394 \pm 393$ & $3199 \pm 299$ & $3137 \pm 312$ \\
\hline Insulin (mIU/l) & $7.4 \pm 4.4$ & $9.5 \pm 3.9^{*}$ & $7.5 \pm 2.3$ & $9.0 \pm 4.2$ \\
\hline Glucagon (pmol/l) & $40.3 \pm 12.1$ & $39.7 \pm 8.5$ & $42.3 \pm 9.5$ & $40.7 \pm 9.5$ \\
\hline Proinsulin (pmol/l) & $5.1 \pm 4.2$ & $6.2 \pm 7.5$ & $3.75 \pm 2.5$ & $4.40 \pm .3$ \\
\hline C peptide (nmol/l) & $0.49 \pm 0.09$ & $0.50 \pm 0.10$ & $0.77 \pm 0.30$ & $0.65 \pm 0.17$ \\
\hline
\end{tabular}

Values are mean \pm SD. BMI, body mass index; WHR, waist : hip ratio; SBP, DBP, systolic and diastolic blood pressures.

${ }^{\star} P<0.05,{ }^{\star \star} P<0.01,{ }^{* \star \star \star} P<0.0001$, compared with before treatment. 


\section{Biochemical and endocrine parameters}

In group D, total cholesterol and HDL-cholesterol increased significantly (both $P<0.05$ ). In group E+CPA, cholesterol did not change significantly. Fasting FFA did not change after any of the treatments. No significant change was observed in triglycerides in group $\mathrm{E}+\mathrm{CPA}$ and a trend towards an increase was seen in group D. Fasting glucose concentration did not change significantly in either group.

As regards steroid hormone concentrations, 17-OH progesterone $(P<0.01)$, DHEA $(P<0.05)$ and $\mathrm{LH}$ $(P<0.01)$ decreased significantly and SHBG increased $(P<0.0001)$ in group D. In group $\mathrm{E}+\mathrm{CPA}$, a significant decrease in LH $(P<0.05)$ was observed. FSH, DHEAS, testosterone, androstenedione and oestradiol concentrations did not change significantly in either group.

IGF-I decreased significantly in group D $(P<0.05)$, but did not change in group E+CPA. IGFBP-3 did not change after either treatment.

Fasting insulin increased significantly in group D $(P<0.05)$. Fasting glucagon, proinsulin and $C$ peptide did not change in any treatment group (Table 1 ).

\section{Metabolic parameters}

Glucose disposal rate $(P<0.004)$, ISI $(P<0.02)$ and MCRg $(P<0.002)$ decreased significantly in group D; in contrast, in group $\mathrm{E}+\mathrm{CPA}$, no change in these parameters was observed. MCRi during clamp did not change significantly in either group. The anti-lipolytic index increased significantly in group E+CPA $(P<0.0001)$ (Fig. 1).

The arginine-stimulated secretion of insulin in the presence of fasting concentrations of glucose (AIRf) and the hyperglycaemia-potentiated secretion of insulin (AIRg) did not change significantly after any treatment. The arginine-stimulated hyperglycaemia-potentiated secretion of glucagon decreased significantly in group D (AGRg: $P<0.01$ ), with no change in group $\mathrm{E}+\mathrm{CPA}$ (Fig. 2).

The disposition index derived from AIRf (Dif) did not change significantly in any group. Those derived from AIRg (Dig) $(P<0.0001)$ and the slope (Dis) $(P<0.0001)$ decreased significantly in group $D$ and did not change in group E+CPA (Fig. 3).

Results from indirect calorimetry demonstrated that resting energy expenditure did not change significantly in either group. Lipid oxidation decreased significantly $(P<0.05)$ in group D (Table 2$)$.

\section{Discussion}

This study demonstrates a significant decline in insulin sensitivity and $\beta$-cell function after a 3-month course of treatment with a combination peroral formulation of oestradiol with CPA (Diane 35), in comparison

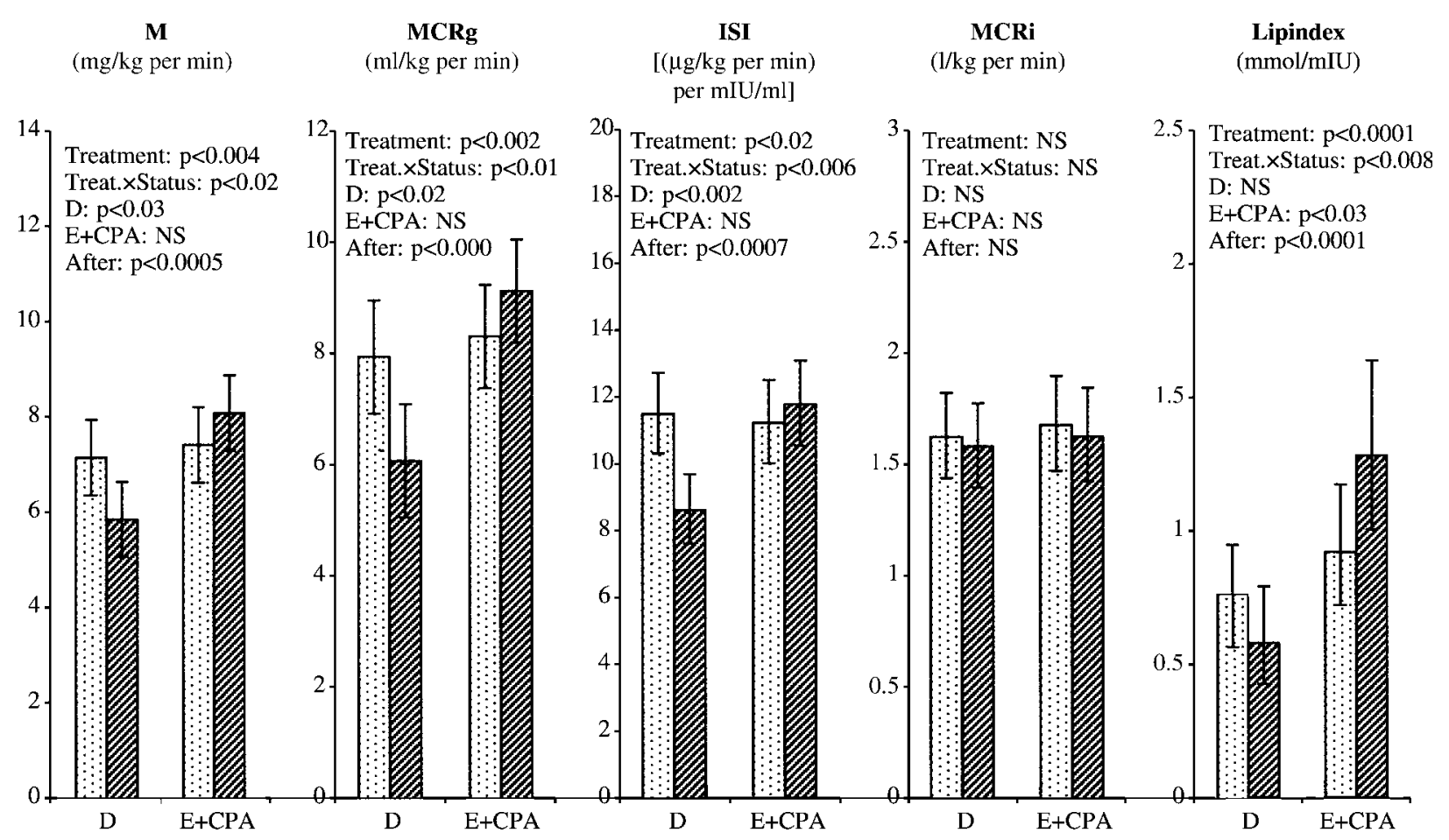

Figure 1 Insulin sensitivity, clearance of insulin and anti-lipolytic index in women with PCOS before and after treatment with either a combination peroral formulation of oestradiol with cyproterone acetate (D) or transdermal oestrogen plus cyproterone acetate $(\mathrm{E}+\mathrm{CPA})$. M, glucose disposal rate; MCRg, metabolic clearance rate of glucose; ISI, insulin sensitivity index; MCRi, posthepatic rate of clearance of plasma insulin; Lipindex, antilipolytic index. 

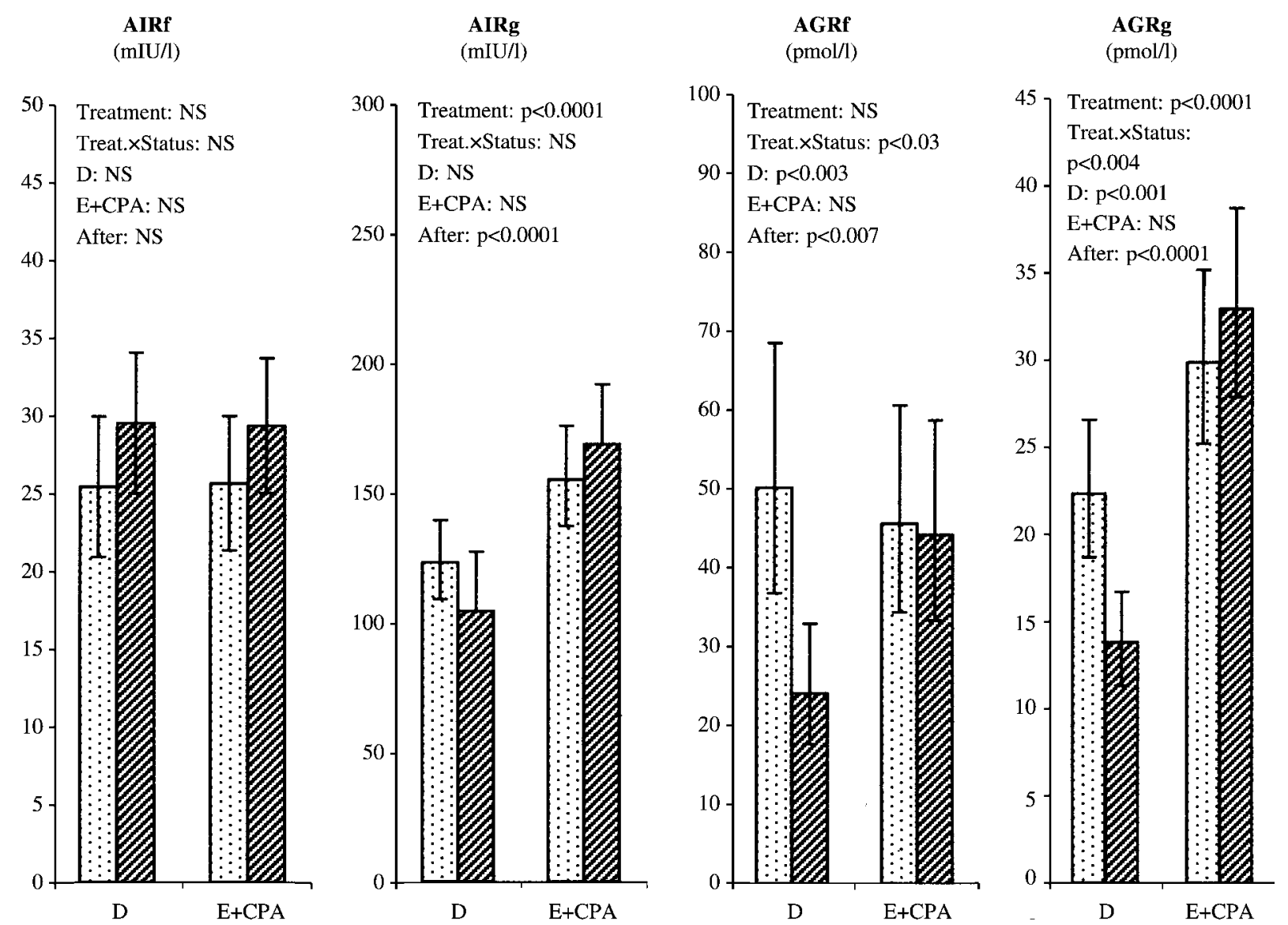

Figure 2 Insulin and glucagon secretion after arginine in women with PCOS before and after treatment with either a combination peroral formulation of oestradiol with cyproterone acetate (D) or transdermal oestrogen plus cyproterone acetate (E+CPA). AIRf, acute insulin response to arginine (fasting glucose concentration); AIRg, acute insulin response to arginine (blood glucose $14 \mathrm{mmol} / \mathrm{l}$ ); AGRf, acute glucagon response to arginine (fasting glucose concentration); AGRg, acute glucagon response to arginine (blood glucose $14 \mathrm{mmol} / \mathrm{l}$ ).

with no significant changes in these parameters after transdermal application of oestrogen (plus oral CPA). The study was conducted in women of fertile years with intact uterus. Both groups received the same gestagen in the same dose, and the results obtained therefore probably reflect the effects of the oestrogens per se.

Hitherto, there has been only scant information regarding insulin sensitivity in women with PCOS after treatment with combined oral contraceptives. The results reported are discrepant. In studies that used clamps as the reference method for the evaluation of insulin resistance, decreased insulin sensitivity was found after the use of combined oral contraceptives in PCOS in some $(10,11,21)$ but not in all studies (24-27).

It is likely that heterogeneity in the populations of patients studied could explain the discrepancies. Diane 35 was recently compared with metformin in both obese and lean women with $\operatorname{PCOS}(26,28)$. Deterioration in glucose tolerance (increase in the area under the glucose curve during an oral glucose tolerance test) after the antiandrogen formulation was found in obese, but not in lean, women with PCOS. The nature of the progestin used could also have an influence: combined oral contraceptives containing norgestimate were not associated with a deterioration in insulin sensitivity (24), whereas the use of combined oral contraceptives containing norethidrone resulted in a significant decrease in insulin sensitivity both in controls and in the women with PCOS (11).

A close association between endogenous oestrogen concentrations and insulin resistance has recently been found in postmenopausal women (29). It would therefore probably be appropriate to take into account the dose of oestrogens when examining the role of different contraceptives in insulin resistance. To our knowledge, there is no study directly comparing low-dose $(30-37.5 \mu \mathrm{g})$ with ultra-low $(20-30 \mu \mathrm{g})$ or extremely low-dose (less than $20 \mu \mathrm{g}$ ) preparations of ethinyloestradiol, either in healthy fertile women or in women affected with PCOS.

In the present study, the arginine-stimulated secretion of glucagon was significantly decreased after 

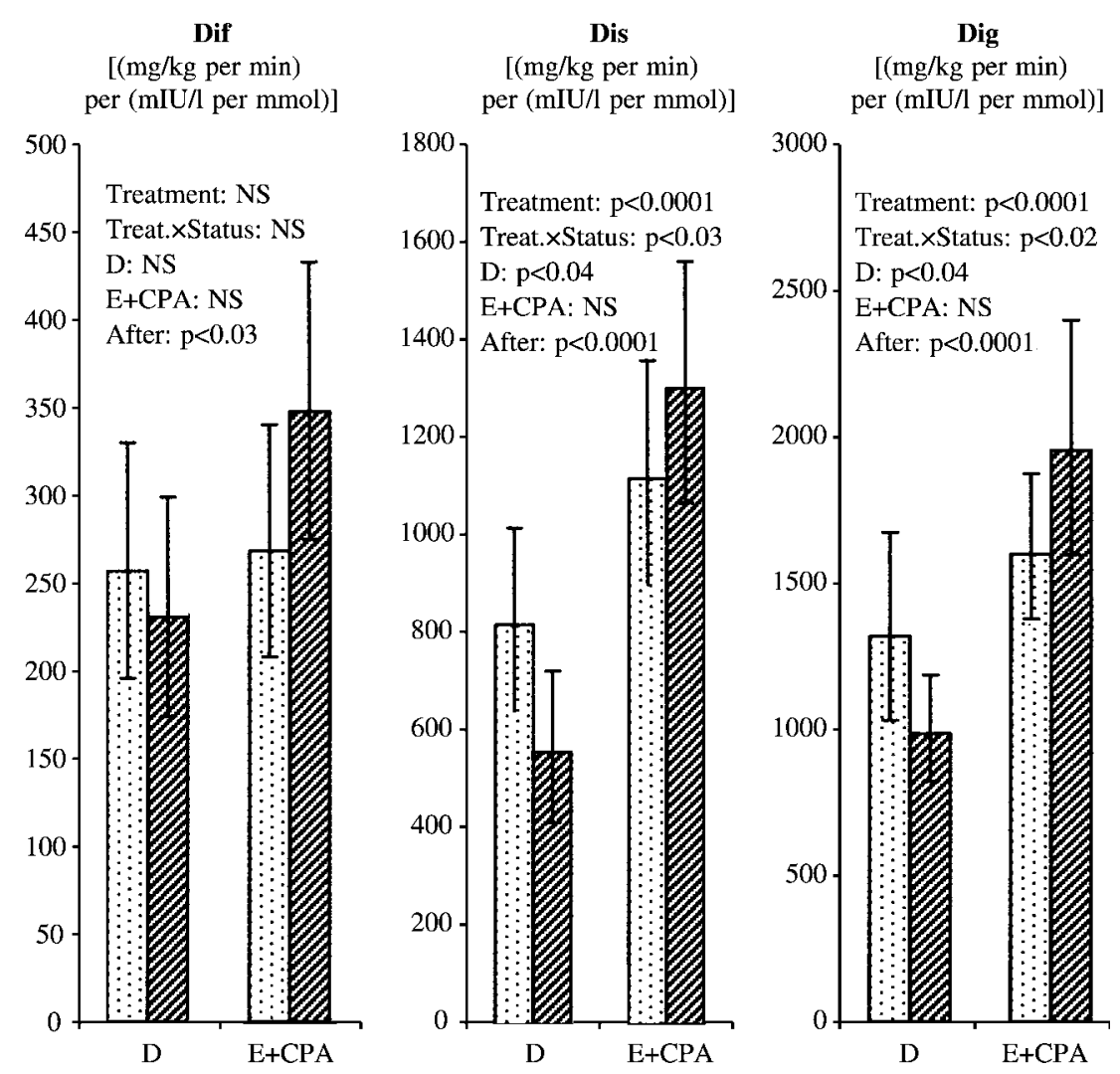

Figure 3 Disposition indices in women with PCOS before and after treatment with either a combination peroral formulation of oestradiol with cyproterone acetate $(D)$ or transdermal oestrogen plus cyproterone acetate $(E+C P A)$. Dif, disposition index derived from the acute insulin responses to arginine (AIR) (fasting glucose concentration; AIRf); Dis, disposition index derived from slope ${ }_{\text {AIR }}$; Dig, disposition index derived from AIR (blood glucose $14 \mathrm{mmol} / \mathrm{l} ; \mathrm{AIRg}$ ).

treatment with the combination peroral formulation of oestradiol with CPA (Diane 35). Inappropriately high glucagon secretion is suspected of having a role in the development of impaired glucose tolerance (30). Our finding of a decreased glucagon secretion is supported by others (31). It is possible that the decrease in glucagon could be a mechanism of adaptation to the decreased insulin sensitivity. In fact, fasting blood glucose declined slightly after the combined oral formulation, probably as a reflection of the decreased hepatic production of glucose in conditions of reduced glucagon concentrations.

It is important to examine insulin resistance and secretion not only separately, but also simultaneously.
$\beta$-Cell dysfunction was found to be an important event in the development of NIDDM (32-34). Insulin sensitivity and secretion are inversely and proportionally related, so that the product of these two parameters (Di) is always a constant (35). The Di is more heritable than either insulin resistance or insulin secretion alone (36). When insulin resistance and secretion were examined repeatedly in individuals who progressed to hyperglycaemia, insulin secretion declined progressively by more than $70 \%$, whereas insulin sensitivity declined by only about $15 \%$ (37). We used the arginine stimulation test to determine various aspects of $\beta$-cell function. The acute insulin response to arginine in the presence of fasting blood glucose concentrations

Table 2 Energy expenditure and substrate oxidation in women with PCOS before and after treatment with either peroral or transdermal oestrogens together with cyproterone acetate.

\begin{tabular}{llcccc}
\hline & \multicolumn{2}{c}{ Peroral } & & \multicolumn{2}{c}{ Transdermal } \\
\cline { 2 - 4 } & \multicolumn{1}{c}{ Before } & After & & Before & After \\
\hline Resting energy expenditure (kcal/24 h) & $1234 \pm 219$ & $1234 \pm 165$ & & $1227 \pm 214$ & $1261 \pm 224$ \\
Lipid oxidation (\%) & $55.7 \pm 12.0^{*}$ & $43.4 \pm 18.0^{*}$ & & $58.0 \pm 15.8$ & $47.4 \pm 21.5$ \\
Saccharide oxidation (\%) & $25.9 \pm 13$ & $33 \pm 17.9$ & & $24.7 \pm 15.7$ & $29.3 \pm 24.0$ \\
Protein oxidation (\%) & $18.7 \pm 8.2$ & $23.4 \pm 9.4$ & & $17.3 \pm 6.7$ & $22.9 \pm 9.5$ \\
\hline
\end{tabular}

Values are means \pm S.D. ${ }^{\star} P<0.05$ compared with before treatment. 
determines the direct and acute $\beta$-cell response to a secretory challenge and is thus related to the exocytic machinery. Slope is a measure of the glucose-induced potentiation of the arginine-induced secretion of insulin (38). We have demonstrated a decrease in the Di (as a

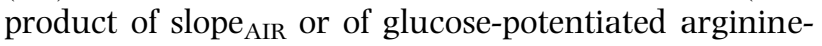
stimulated insulin secretion and the ISI) and no change in the $\mathrm{Di}$ derived from arginine-stimulated secretion of insulin in the presence of fasting concentrations of blood glucose after peroral treatment with oestrogen. Thus insufficient compensation of the insulin resistance is probably related, not to inefficient exocytosis, but to the mechanism of glucose recognition.

We observed a significant decline in IGF-I after peroral oestrogens. This is in accordance with the experience of others (39), who found a decrease in IGF-I in postmenopausal women after oral, but not transdermal, oestrogens. A decrease in IGF-I was also observed after combined oral contraceptive use in women of fertile age $(40,41)$.

The decline in lipid oxidation after peroral oestrogens and the improvement in the anti-lipolytic index after transdermal oestrogens are in accordance with studies conducted in both growth hormone deficient and postmenopausal women and comparing oral and transdermal administration of oestrogen. Oral oestrogens have been shown to act as growth hormone antagonists, leading to the suppression of postprandial lipid oxidation and a decline in IGF-I $(42,43)$.

HDL-cholesterol and total cholesterol increased significantly after peroral oestrogens, and triglycerides also tended to increase. In contrast, lipid concentrations did not change significantly after transdermal treatment. These data are in agreement with previous observations (44-48). Dyslipidaemia (decrease in HDLcholesterol and increase in triglycerides) is common in women with PCOS $(49,50)$. The question still remains whether these women are at increased risk for cardiovascular disease (51). Conversely, it has previously been reported that combined oral contraceptives may increase the risk of myocardial infarction (52). To date, there are no studies specifically addressing the use of combined oral contraceptives in women with PCOS and the impact of their use on cardiovascular morbidity and mortality.

Peroral oestrogens significantly increased SHBG concentrations and thus the free androgen index declined markedly. The increase in SHBG is a result of the hepatic effects of oestrogens (the stimulation of hepatic proteosynthesis). These observations are in accordance with the findings of previous studies (47). Testosterone concentrations tended to decline after transdermal application of oestrogen. LH declined significantly after either oral or transdermal treatment. Thus more marked androgen suppression was achieved with peroral oestrogen treatment. Further investigations are required as to whether these effects have any long-term consequences regarding hirsutism and acne. The present study was designed primarily to evaluate the metabolic effects of either oral or transdermal administration of oestrogens and androgenic symptoms were thus not evaluated systematically.

In conclusion, peroral oestrogens are associated with significant deterioration in insulin sensitivity and secretion in women with PCOS. These undesirable metabolic effects were not present when oestrogens were applied transdermally.

\section{Acknowledgements}

This work was supported by a grant fom the Grant Agency of the Czech Ministry of Health, No. NB $6696 / 3$. Some data were presented in part at $22 \mathrm{nd}$ Joint Meeting of the British Endocrine Societies, Glasgow, 24-26 March 2003 and at the 6th European Congress of Endocrinology, Lyon, 26-30 April 2003.

The excellent technical assistence of Mrs Jana Novotna, Romana Bajtlova, Nada Karaskova and Helena Vratna is gratefully acknowledged.

\section{References}

1 Diamanti-Kandarakis E, Kouli CR, Bergiele AT, Filandra FA, Tsianateli TC, Spina GG et al. A survey of the polycystic ovary syndrome in the Greek island of Lesbos: hormonal and metabolic profile. Journal of Clinical Endocrinology and Metabolism $1999 \mathbf{8 4}$ 4006-4011.

2 Knochenhauer ES, Key TJ, Kahsar-Miller M, Waggoner W, Boots LR \& Azziz R. Prevalence of the polycystic ovary syndrome in unselected black and white women of the southeastern United States: a prospective study. Journal of Clinical Endocrinology and Metabolism $1998 \mathbf{8 3} 3078-3082$.

3 Dunaif A, Segal KR, Futterweit W \& Dobrjansky A. Profound peripheral insulin resistance, independent of obesity, in polycystic ovary syndrome. Diabetes 198938 1165-1174.

4 Dunaif A, Graf M, Mandeli J, Laumas V \& Dobrjansky A. Characterization of groups of hyperandrogenic women with acanthosis nigricans, impaired glucose tolerance, and/or hyperinsulinemia. Journal of Clinical Endocrinology and Metabolism $1987 \mathbf{6 5}$ 499-507.

5 Weerakiet S, Srisombut C, Bunnag P, Sangtong S, Chuangsoongnoen N \& Rojanasakul A. Prevalence of type 2 diabetes mellitus and impaired glucose tolerance in Asian women with polycystic ovary syndrome. International Journal of Gynaecology and Obstetrics 200175 177-184.

6 Norman RJ, Masters L, Milner CR, Wang JX \& Davies MJ. Relative risk of conversion from normoglycaemia to impaired glucose tolerance or non-insulin dependent diabetes mellitus in polycystic ovarian syndrome. Human Reproduction $2001 \mathbf{1 6}$ 1995-1998

7 Legro RS, Kunselman AR, Dodson WC \& Dunaif A. Prevalence and predictors of risk for type 2 diabetes mellitus and impaired glucose tolerance in polycystic ovary syndrome: a prospective, controlled study in 254 affected women [see comments]. Journal of Clinical Endocrinology and Metabolism $1999 \mathbf{8 4} 165-169$.

8 Ehrmann DA, Barnes RB, Rosenfield RL, Cavaghan MK \& Imperial J. Prevalence of impaired glucose tolerance and diabetes in women with polycystic ovary syndrome. Diabetes Care 199922 141-146.

9 Nader S, Riad-Gabriel MG \& Saad MF. The effect of a desogestrelcontaining oral contraceptive on glucose tolerance and leptin concentrations in hyperandrogenic women. Journal of Clinical Endocrinology and Metabolism 199782 3074-3077. 
10 Dahlgren E, Landin K, Krotkiewski M, Holm G \& Janson PO. Effects of two antiandrogen treatments on hirsutism and insulin sensitivity in women with polycystic ovary syndrome. Human Reproduction $1998132706-2711$.

11 Korytkowski MT, Mokan M, Horwitz MJ \& Berga SL. Metabolic effects of oral contraceptives in women with polycystic ovary syndrome. Journal of Clinical Endocrinology and Metabolism $1995 \mathbf{8 0}$ 3327-3334.

12 Vehkavaara S, Westerbacka J, Hakala-Ala-Pietila T, Virkamaki A, Hovatta $\mathrm{O} \&$ Yki-Jarvinen $\mathrm{H}$. Effect of estrogen replacement therapy on insulin sensitivity of glucose metabolism and preresistance and resistance vessel function in healthy postmenopausal women. Journal of Clinical Endocrinology and Metabolism 2000 85 4663-4670.

13 Duncan AC, Lyall H, Roberts RN, Petrie JR, Perera MJ, Monaghan S et al. The effect of estradiol and a combined estradiol/progestagen preparation on insulin sensitivity in healthy postmenopausal women. Journal of Clinical Endocrinology and Metabolism $1999842402-2407$.

14 Karjalainen A, Paassilta M, Heikkinen J, Backstrom AC, Savolainen M \& Kesaniemi YA. Effects of peroral and transdermal oestrogen replacement therapy on glucose and insulin metabolism. Clinical Endocrinology (Oxford) 200154 165-173.

15 Lindheim SR, Duffy DM, Kojima T, Vijod MA, Stanczyk FZ \& Lobo RA. The route of administration influences the effect of estrogen on insulin sensitivity in postmenopausal women. Fertility and Sterility $1994 \mathbf{6 2} 1176-1180$.

16 Araujo DA, Farias ML \& Andrade AT. Effects of transdermal and oral estrogen replacement on lipids and glucose metabolism in postmenopausal women with type 2 diabetes mellitus. Climacteric 20025 286-292.

17 Vexiau P, Fiet J, Conard J, Abramovici Y, Boudou P, Hardy N et al. 17 Beta-estradiol: oral or parenteral administration in hyperandrogenic women? Metabolic tolerance in association with cyproterone acetate. Fertility and Sterility 199563 508-515.

18 Dunaif A. Insulin resistance and the polycystic ovary syndrome: mechanism and implications for pathogenesis. Endocrine Reviews $199718774-800$.

19 Cibula D, Skrha J, Hill M, Fanta M, Haakova L, Vrbikova J et al. Prediction of insulin sensitivity in nonobese women with polycystic ovary syndrome. Journal of Clinical Endocrinology and Metabolism $2002875821-5825$.

20 Larsson H \& Ahren B. Glucose-dependent arginine stimulation test for characterization of islet function: studies on reproducibility and priming effect of arginine. Diabetologia $1998 \mathbf{4 1}$ $772-777$.

21 Vrbikova J, Hill M, Starka L, Cibula D, Bendlova B, Vondra K et al. The effects of long-term metformin treatment on adrenal and ovarian steroidogenesis in women with polycystic ovary syndrome. European Journal of Endocrinology 2001 144 619-628.

22 Kahn SE, Prigeon RL, McCulloch DK, Boyko EJ, Bergman RN, Schwartz MW et al. Quantification of the relationship between insulin sensitivity and beta-cell function in human subjects. Evidence for a hyperbolic function. Diabetes $1993 \mathbf{4 2}$ $1663-1672$

23 Jacob S, Stumvoll M, Becker R, Koch M, Nielsen M, Loblein K et al. The PPARgamma2 polymorphism pro12Ala is associated with better insulin sensitivity in the offspring of type 2 diabetic patients. Hormone Metabolic Research 200032 413-416.

24 Cibula D, Sindelka G, Hill M, Fanta M, Skrha J \& Zivny J. Insulin sensitivity in non-obese women with polycystic ovary syndrome during treatment with oral contraceptives containing low-androgenic progestin. Human Reproduction 200217 76-82.

25 Armstrong VL, Wiggam MI, Ennis CN, Sheridan B, Traub AI, Atkinson $\mathrm{AB}$ et al. Insulin action and insulin secretion in polycystic ovary syndrome treated with ethinyl oestradiol/cyproterone acetate. Quarterly Journal of Medicine 200194 31-37.

26 Morin-Papunen L, Vauhkonen I, Koivunen R, Ruokonen A, Martikainen H \& Tapanainen JS. Metformin versus ethinyl estradiol-cyproterone acetate in the treatment of nonobese women with polycystic ovary syndrome: a randomized study. Journal of Clinical Endocrinology and Metabolism 200388 148-156.

27 Scheen AJ, Jandrain BJ, Humblet DM, Jaminet CB, Gaspard UJ \& Lefebvre PJ. Effects of a 1-year treatment with a low-dose combined oral contraceptive containing ethinyl estradiol and cyproterone acetate on glucose and insulin metabolism. Fertility and Sterility $1993 \mathbf{5 9}$ 797-802.

28 Morin-Papunen LC, Vauhkonen I, Koivunen RM, Ruokonen A, Martikainen HK \& Tapanainen JS. Endocrine and metabolic effects of metformin versus ethinyl estradiol-cyproterone acetate in obese women with polycystic ovary syndrome: a randomized study. Journal of Clinical Endocrinology and Metabolism $2000 \mathbf{8 5}$ 3161-3168.

29 Kalish GM, Barrett-Connor E, Laughlin GA \& Gulanski BI. Association of endogenous sex hormones and insulin resistance among postmenopausal women: results from the Postmenopausal Estrogen/Progestin Intervention Trial. Journal of Clinical Endocrinology and Metabolism $2003 \mathbf{8 8}$ 1646-1652.

30 Larsson H \& Ahren B. Glucose intolerance is predicted by low insulin secretion and high glucagon secretion: outcome of a prospective study in postmenopausal Caucasian women. Diabetologia 200043 194-202.

31 Larsson H \& Ahren B. Insulin resistant subjects lack islet adaptation to short-term dexamethasone-induced reduction in insulin sensitivity. Diabetologia 199942 936-943.

32 Kahn SE. Beta cell failure: causes and consequences. International Journal of Clinical Practice Supplement 2001123 13-18.

33 Kahn SE. Clinical review 135: the importance of beta-cell failure in the development and progression of type 2 diabetes. Journal of Clinical Endocrinology and Metabolism 2001 86 4047-4058.

34 van Haeften TW. Early disturbances in insulin secretion in the development of type 2 diabetes mellitus. Molecular and Cellular Endocrinology $2002197197-204$.

35 Kahn SE, Prigeon RL, McCulloch DK, Boyko EJ, Bergman RN, Schwartz MW et al. Quantification of the relationship between insulin sensitivity and beta-cell function in human subjects. Evidence for a hyperbolic function. Diabetes $1993 \mathbf{4 2} 1663-1672$.

36 Colilla S, Cox NJ \& Ehrmann DA. Heritability of insulin secretion and insulin action in women with polycystic ovary syndrome and their first degree relatives. Journal of Clinical Endocrinology and Metabolism $2001862027-2031$.

37 Weyer C, Bogardus C, Mott DM \& Pratley RE. The natural history of insulin secretory dysfunction and insulin resistance in the pathogenesis of type 2 diabetes mellitus. Journal of Clinical Investigation $1999 \mathbf{1 0 4} 787-794$.

38 Ahren B \& Larsson H. Quantification of insulin secretion in relation to insulin sensitivity in nondiabetic postmenopausal women. Diabetes 200251 (Suppl. 1) S202-S211.

39 Paassilta M, Karjalainen A, Kervinen K, Savolainen MJ, Heikkinen J, Backstrom AC et al. Insulin-like growth factor binding protein-1 (IGFBP-1) and IGF-I during oral and transdermal estrogen replacement therapy: relation to lipoprotein(a) levels. Atherosclerosis $2000149157-162$.

40 Balogh A, Kauf E, Vollanth R, Graser G, Klinger G \& Oettel M. Effects of two oral contraceptives on plasma levels of insulin-like growth factor I (IGF-I) and growth hormone (hGH). Contraception $200062259-269$

41 Westwood M, Gibson JM, Pennells LA \& White A. Modification of plasma insulin-like growth factors and binding proteins during oral contraceptive use and the normal menstrual cycle. American Journal of Obstetrics and Gynecology 1999180 530-536.

42 O'Sullivan AJ, Crampton LJ, Freund J \& Ho KK. The route of estrogen replacement therapy confers divergent effects on substrate oxidation and body composition in postmenopausal women. Journal of Clinical Investigation $1998 \mathbf{1 0 2} 1035-1040$.

43 Wolthers T, Hoffman DM, Nugent AG, Duncan MW, Umpleby M \& Ho KK. Oral estrogen antagonizes the metabolic actions of growth hormone in growth hormone-deficient women. American Journal of Physiology Endocrinology and Metabolism 2001 281 E1191-E1196. 
44 Vexiau P, Vexiau-Robert D, Martineau I, Hardy N, Villette JM, Fiet $\mathrm{J}$ et al. Metabolic effect at six and twelve months of cyproterone acetate ( $2 \mathrm{mg}$ ) combined with ethinyl estradiol (35 micrograms) in 31 patients. Hormone and Metabolic Research 199022 241-245.

45 Prelevic GM, Wurzburger MI, Trpkovic D \& Balint-Peric L. Effects of a low-dose estrogen-antiandrogen combination (Diane-35) on lipid and carbohydrate metabolism in patients with polycystic ovary syndrome. Gynecological Endocrinology 1990 4 157-168.

46 Falsetti L \& Galbignani E. Long-term treatment with the combination ethinylestradiol and cyproterone acetate in polycystic ovary syndrome. Contraception $199042611-619$.

47 Falsetti L, Gambera A \& Tisi G. Efficacy of the combination ethinyl oestradiol and cyproterone acetate on endocrine, clinical and ultrasonographic profile in polycystic ovarian syndrome. Human Reproduction 200116 36-42.

48 Falsetti L \& Pasinetti E. Effects of long-term administration of an oral contraceptive containing ethinylestradiol and cyproterone acetate on lipid metabolism in women with polycystic ovary syndrome. Acta Obstetrica et Gynaecologica Scandinavica $1995 \mathbf{7 4}$ $56-60$.
49 Talbott E, Guzick D, Clerici A, Berga S, Detre K, Weimer K et al. Coronary heart disease risk factors in women with polycystic ovary syndrome. Arteriosclerosis, Thrombosis and Vacsular Biology $199515821-826$.

50 Conway GS, Agrawal R, Betteridge DJ \& Jacobs HS. Risk factors for coronary artery disease in lean and obese women with the polycystic ovary syndrome. Clinical Endocrinology 1992 37 119-125.

51 Wild RA. Polycystic ovary syndrome: a risk for coronary artery disease? American Journal of Obstetrics and Gynecology $2002 \mathbf{1 8 6}$ 35-43.

52 Tanis BC, van den Bosch MA, Kemmeren JM, Cats VM, Helmerhorst FM, Algra A et al. Oral contraceptives and the risk of myocardial infarction. New England Journal of Medicine 2001 345 1787-1793.

Received 7 August 2003

Accepted 28 October 2003 